
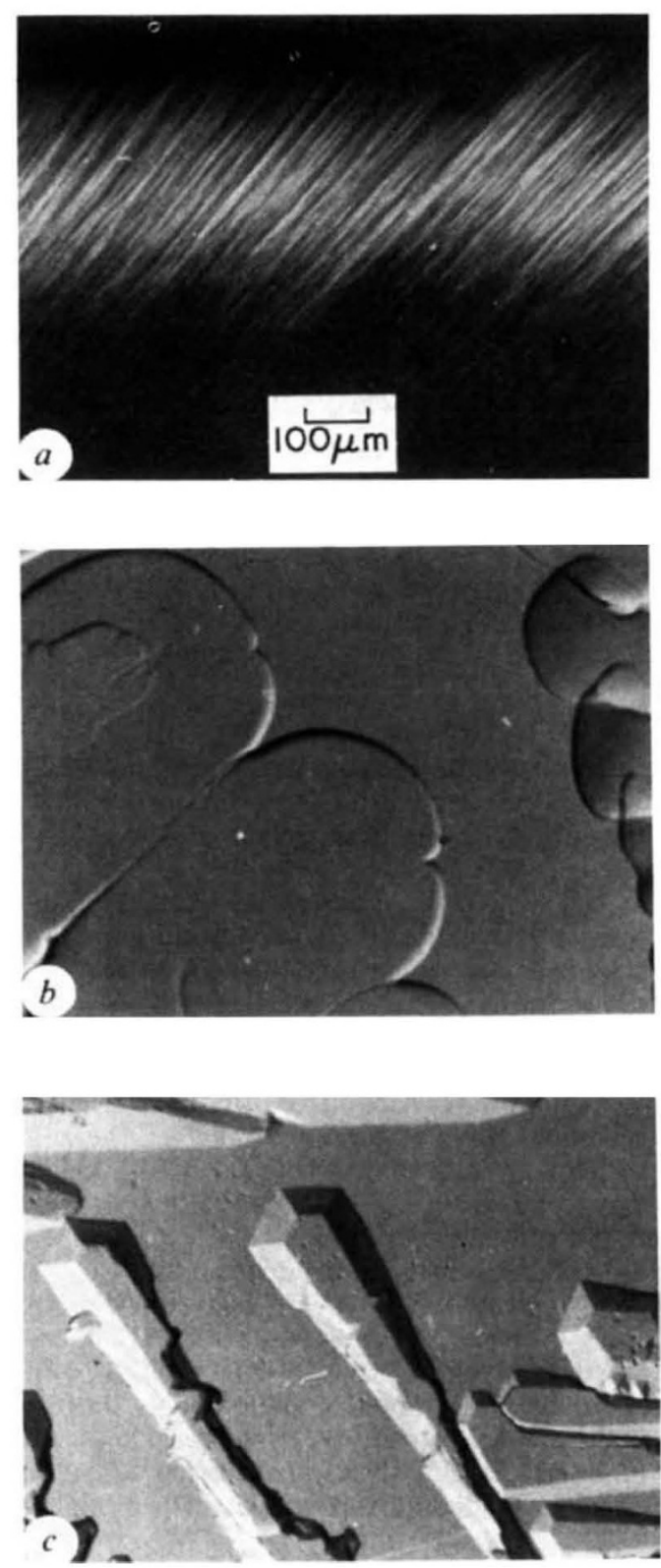

Fig. 2 Effect of the glycopeptides on crystal growth habit. $a$, The freezing interface of a $1 \%$ (by weight) solution of glycopeptides 1-5; water above, ice below. The fibres are parallel to the $c$-axis of the ice. $b$, Freezing of pure water at low supercooling. The $c$-axis is perpendicular to the plane of the photograph, and all interfaces are rounded except the basal face. Growth is slowest parallel to the $c$-axis. $c$, On freezing of a $2.5 \times 10^{-5} \mathrm{~g} \mathrm{~g}^{-1}$ solution of glycopeptides $1-5\left(\sim 2 \times 10^{-8} \mathrm{M}\right)$ at low supercooling, $\{10 \overline{1} \mathrm{x}\}$ faces develop. The $c$-axis, again, is perpendicular to the plane of the photograph. The scale in $a$ applies to all photographs.

freezing hysteresis [polyethylene glycol (MW 6,000), dextran (MW 9,400 and 20,000) and polyvinyl pyrrolidone (MW $40,000)$ ] were tested and found not to produce growth habit modification. A peptide antifreeze isolated from winter flounder blood $^{8}$ that also produces freezing hysteresis, has a similar effect on ice growth habit at low concentrations. This habit modification effect might be the basis of a very simple and sensitive test for activity of a potential antifreeze material, as the amount needed to produce and detect the effect is very small.

We have also found that concentrations of AFGP as low as $10^{-9} \mathrm{~g} \mathrm{~g}^{-1}\left(\sim 10^{-12} \mathrm{M}\right)$ are extremely effective in preventing recrystallization of ice, whereas the same organic compounds as noted above were found to have little effect on recrystallization. This strong effect of very small amounts of AFGPs on recrystallization might have application in the preservation of frozen foods or medical materials ${ }^{15}$. Although the importance of the recrystallization process per se has not been firmly established, it has been suggested as a possible role of the AFGPs in the survival of some freeze-tolerant insects (J. Duman, private communication).

The mechanism by which the AFGP inhibits freezing is not understood. Certainly it bonds at the ice-water interface, and it has been suggested that it might inhibit the lateral growth of steps $^{4,6,8}$. If this were the case, it is not clear why low concentrations stimulate the development of the crystal faces that are observed. Jackson ${ }^{16}$ calculated that the equilibrium structures of all surfaces of ice should be molecularly rough except the basal face, and this fits the observation that only basal faces appear in ice growth from pure water or, in fact, from any water solutions of which we are aware except those of the antifreeze proteins. An explanation of why the low amounts of AFGP produce the new crystal faces may be a key to understanding the freezing hysteresis itself.

Strong effects of small amounts of impurities on the growth habit of crystals grown from solution or from vapour are common. However, this is the only example of which we are aware, of such a striking impurity effect in crystal growth from the melt. It is also, as far as we know, the only example of freezing point hysteresis induced by a molecular solute. Some polymeric solutes that form gels are known to induce a similar freezing hysteresis $^{17}$.

This work was supported in part by NSF grant DPP 81-16917 (to A.L.D.). The National Center for Atmospheric Research is sponsored by the NSF.

Received 15 August; accepted 22 December 1983

1. DeVries, A. L. Science 172, 1152-1155 (1971).

. DeVries, A. I. in Biochemical and Biophysical Perspectives in Marine Biology Vol. 1 (eds Sargent, J. S. \& Mallins, D. W.) 289-330 (Academic, London, 1974)

. Feeney, R. E. Am. Scient. 62, 712-719 (1974).

4. DeVries, A. L. \& Lin, Y. in Adaptation Within Antarctic Ecosystems, 439-458 (Gulf Publ. Co., Houston, 1977)

5. Feeney, R. E. \& Ych, Y. Adv. Protein Chem. 32, 191-282 (1978)

6. DeVries, A. L. in Animals and Environmensal Fitness (ed. Gilles, R.) 583-607 (Pergamon, Oxford, 1980).

7. Raymond, J. A. \& DeVries, A. L. Proc. natn. Acad. Sci. U.S.A. 74, 2589-2593 (1977) 8. DeVries, A. L. Comp. Biochem. Physiol. 73A, 627-640 (1982).

9. Schrag, J. D. \& DeVries, A. L. Comp. Biochem. Physiol. 74A, 381-385 (1983).

10. Hew, C. L., Fletcher, G. L \& Ananthanarayanan, V. S. Can. J. Biochem. 58, 377-383 (1980).

11. Ananthanarayanan, V. S. \& Hew, C. L. in Biomolecular Structure, Conformation, Function and Evolution Vol. 2 (ed. Srinivasan, R.) 191-198 (Pergamon, Oxford, 1980).

12. Slaughter, D., Fletcher, G. I.., Ananthanarayanan, V. S. \& Hew, C. L. J. biol. Chem. 256, 2022-2026 (1981)

13. Jones, D. R. H. Metals Mater, 6, 312-313 (1972).

14. Knight, C. A. \& LaChappele, E. R. J. Glaciol. 9, 87-101 (1970).

15. Mazur, P. Science 168, 939949 (1970).

16. Jackson, K. A. in Liquid Metals and Solidification, 174-186 (Am. Soc. for Metals, Cleveland, 1958).

17. Kuhn, W. Helv. chim. Acta 39, 1071-1086 (1956).

\title{
Nature in Tokyo
}

Nature has opened an office in Tokyo. Dr Alun Anderson, for the past few years in charge of the News and Views section of Nature, will be in charge of the office for an initial period of one year. By this means, Nature hopes more efficiently to cover news of developments in Japan and also to provide tangible help to Japanese scientists wishing to submit research papers or other communications to Nature.

Dr Anderson's address is Nature, Macmillan Shuppan KK, Eikow Building, 10-9, Hongo 1-chome, Bunkyo-ku, Tokyo 113 (Telephone (03) 816 3756/7; Telex JATOKJ32121 MSKK). 